This is an Accepted Manuscript of an article published by Taylor \& Francis in Qualitative Research in Sport, Exercise and Health on 25/06/17, available online:

http://www.tandfonline.com/doi/full/10.1080/2159676X.2017.1341947 


\section{Educating and Supporting Tennis Parents: An Action Research Study}

Sam N. Thrower, Chris G. Harwood and Christopher M. Spray

Loughborough University

Author Note

Sam N. Thrower, Sport, Nutrition \& Exercise Sciences Department, Kingston University, Kingston Upon Thames, United Kingdom, KT1 2EE., Email: s.thrower@kingston.ac.uk

Chris N. Harwood, School of Sport, Exercise \& Health Sciences, Loughborough University, Loughborough, United Kingdom, LE11 3TU. Tel: +44 01509 226342, Email: c.g.harwood@lboro.ac.uk

Christopher N. Spray, School of Sport, Exercise \& Health Sciences, Loughborough University, Loughborough, United Kingdom, LE11 3TU. Tel: +44 01509 226339, Email: c.m.spray@1boro.ac.uk

Biographical Note:

Sam Thrower is a Lecturer in Sport Psychology, Chris Harwood is a Professor in Applied Sport Psychology and Chris Spray is a Reader in Sport \& Exercise Psychology

\section{Correspondence:}

Correspondence concerning this article should be addressed to Sam N. Thrower, Sport, Nutrition \& Exercise Sciences Department, Kingston University, Penrhyn Road, Kingston upon Thames, Surrey, United Kingdom, KT1 2EE. Email: s.thrower@kingston.ac.uk.

Word Count: 8425 


\section{Educating and Supporting Tennis Parents: An Action Research Study}

\section{Abstract}

This study examined the effectiveness of an evidence-based sport parent education programme designed to meet the stage-specific needs of British tennis parents. Using an organisational action research framework, six workshops were run over a 12-week period for tennis parents with children between the ages of 5 and 10 years. Workshops took place in three high performance tennis centres and had an average attendance of 22 parents. Data were collected using participant diaries, emails, social validation feedback forms, reflective diaries, and post-programme focus groups $(n=19)$. The impact and effectiveness of the programme was evaluated qualitatively using a thematic analysis. Results indicated that the programme was effective in enhancing tennis parents' perceived knowledge, affective states, and skills across a range of learning objectives. Results also provide a unique understanding of parents' experiences of participating in a sport parent education programme. Insights are provided for practitioners in relation to the design, content, and delivery of future sport parent education programs.

Key Words: parents, tennis, action research, childhood, intervention 


\section{Introduction}

Research within the area of youth sport parenting has grown considerably within the last decade (see Holt and Knight 2014 for a review). Researchers have provided an in-depth understanding of coaches' and players' perceptions of positive and negative parenting practices (e.g., Gould et al. 2008, Knight et al. 2010), the stressors, emotions, and experiences associated with parenting in youth sport (e.g., Dorsch et al. 2015, Harwood and Knight 2009a, 2009b), the positive and negative styles and behaviours parents display (e.g., Knight and Holt 2014, Lauer et al. 2010) and the education and support parents need to improve their experiences and involvement (Knight and Holt 2013a, 2013b, [Authors] 2016). These studies have collectively illustrated the complex and challenging nature of parenting in youth sport and highlighted how parents could benefit from stage-specific education and support, particularly when they first enter into an organised youth sport system.

Despite this, there are somewhat surprisingly only a small number of published intervention studies with sport parents (i.e., Dorsch et al. 2016, Harwood and Swain 2002, Smoll et al. 2007). Early interventions tended to focus on creating task-orientated motivational climates involving coaches, players, and parents through single (Smoll et al. 2007) and season-long interventions (Harwood and Swain 2002). Educational sessions focused on enhancing parents' knowledge and awareness of goal orientations, process goal setting, verbal and non-verbal communication strategies, and behavioural guidelines for parents. Findings revealed how these interventions were successful in improving young athletes' self-reported task involvement, cognitive appraisal, selfregulation, and self-efficacy (Harwood and Swain 2002), as well as lowering cognitive and somatic anxiety (Smoll et al. 2007). Despite making an important contribution to the literature, neither of these studies evaluated the effectiveness of the interventions on parental outcomes, and as a result the relative contribution of the parent (and coach) in relation to these results was unclear.

Dorsch and colleagues (2016) recently addressed this limitation by designing, implementing and assessing the impact of a parent education programme for Canadian youth soccer parents. 
Based on an extensive literature review, the evidence-based education programme consisted of a 33-page 'sport parent guide' and a 45-minute 'sport parent seminar' on youth sport participation, developmental models of sport participation, participation rates in sport, communication, working with coaches, sport parent behaviour, and tips for positive sport parenting. Adopting a quasiexperimental design, 81 parents were assigned to a full $(n=18)$, partial $(n=36)$ or nonimplementation $(n=27)$ condition. Parents in the full-implementation group attended the 'sport parent seminar' and were given the 'sport parent guide' whilst those in the partial-implementation condition were only given the guide. Findings encouragingly revealed how parents in the full implementation group demonstrated more support and warmth as well as less pressure and conflict following the program. Furthermore, these parents also had children who reported more enjoyment, higher perceptions of competence, and lower levels of stress.

Interestingly, the recent shift away from longitudinal individual interventions (Harwood and Swain 2002) towards shorter group-based workshop initiatives (Dorsch et al. 2016, Smoll et al. 2007) appears to reflect the current situation in youth sport where limited resources are being made available for parent education. Therefore, it is likely that group-based interventions are viewed as a more time-effective, cost-efficient and sustainable way of educating and supporting parents in the current youth sport climate. However, although the aforementioned studies have provided initial evidence to suggest that group-based sport parent interventions can positively impact on parent (and child) outcomes, the reliance on quantitative experimental designs (i.e., Dorsch et al. 2016, Smoll et al. 2007) means that relatively little is currently known about the learning mechanisms (i.e., changes in knowledge, affect or skill) through which these programmes achieve positive behavioural outcomes. In addition to this, there is a lack of understanding of parents' experiences of engaging in group-based education programmes. Furthermore, the specific topics and content covered in these existing programmes seem to have been entirely dictated by the service providers and based on assumed needs rather than the actual needs of the parents in these youth sport contexts. Taking this into consideration, it is clear that our understanding of the parenting experience 
is currently some way ahead of published intervention research in the sport parent literature. This dichotomy is clearly evident in junior-tennis where there currently exists an in-depth understanding of tennis parents' experiences, involvement and educational needs ([Authors] 2016), and yet published field-based intervention studies specifically with tennis parents are conspicuous by their absence in the literature (Harwood and Knight 2015). This realisation caused Harwood and Knight (2015) to encourage applied researchers, practitioners, and sports organisations to use this body of literature to provide proactive interventions, which meet parents' stage-specific education and support needs, and thus enhance their expertise. The purpose of this study, therefore, was to develop, implement and evaluate the effectiveness of a field-based tennis parent education programme designed to meet the needs of British tennis parents during the initial stage of children's involvement (i.e., mini-tennis) (See [Authors] 2016). A qualitative organisational action research design was used to answer the following research questions: 'What effect does a tennis parent education programme have on parents' knowledge, affect and skills?' and 'what are parents experiences of participating in a tennis parent education programme?'

\section{Methodology}

\section{Organisational Action Research}

Action research has been defined as "a participatory, democratic process concerned with developing practical knowing in the pursuit of worthwhile human purposes, grounded in a participatory worldview" (Reason and Bradbury 2001, p1). Therefore, action research seeks to reintegrate theory and practice, researcher and participant, everyday experience and academic knowledge (Reason and Bradbury 2001). Action research studies are being increasingly used within sport to provide long-term solutions to the real life needs of participants (e.g., Hill et al. 2011). The current study was grounded in the organisational action research tradition, which aims to solve a particular problem, or directly improve an area of an organisation (in this case, tennis parenting within high performance centres) through 'scholarly consultancy' (Wagstaff et al. 2013). In this role, researchers act as 'change agents' in real life situations and empower those operating within 
the organisation by giving participants ownership of the change process. Therefore, the attitude was to work 'with' not 'on' participants by adopting the mind-set that 'we know' and 'they know' (Herr and Anderson 2005). As a result, the first author adopted an 'outsider' (i.e., academic) in collaboration with insiders' positionality (Herr and Anderson 2005).

\section{Organisation and Participants}

Three high performance tennis centres in the United Kingdom (one with international status) were purposefully selected for four reasons: Firstly, the leading author had an in-depth knowledge of the organisations and the parents within them having previously conducted research in these settings (see [Authors] 2016). Secondly, rapport, mutual respect and credibility had already been developed between the author and the directors, coaches, and parents within each centre (see [Authors] 2016). Thirdly, the 'areas for action' (Gilbourne and Richardson 2005) had also been previously been identified (see [Authors] 2016). Finally, the directors in each centre were committed to educating and supporting tennis parents (Wagstaff et al. 2013).

In line with the purpose of the study, parents of mini-tennis players (a form of tennis played on smaller courts, with modified equipment, for children aged between 5-10 years) across all three high performance centres were invited by email to attend an introductory workshop. Of approximately 150 parents who were invited, 17 attended an introductory workshop and 16 subsequently agreed to partake in the study. Over the course of the study a total of 31 parents (see Table 1) attended at least one workshop, with the average workshop attendance across all three centres being 22. Two of the participants completed all seven workshops, with 22 parents completing four or more. Following the 12-week intervention, all participants were given the opportunity to participate in a focus group. A total of 19 parents (15 female, 4 male) participated in one of the three focus groups (See Table 1). [Table 1 near here]

\section{Procedure}

The '[University Name] Tennis Parent Education Programme' and its learning objectives (see Table 2) (Anderson et al. 2001) were derived from the needs of British tennis parents ([Authors] 
2016) and informed by other relevant tennis parent literature (e.g., Harwood and Knight 2009a, 2009b, Harwood and Knight 2015, Knight and Holt 2013a, 2013b). This qualitative scouting was a necessary preliminary step as programmes in unfamiliar settings/contexts can fail to connect with reality when implemented (Needleman and Needleman 1996). Specifically, the procedure was guided by Evans et al.'s (2000) criteria for action research in sport and involved engaging in an ongoing cyclic process of planning, implementing, monitoring, reflecting, and evaluating (Evans et al. 2000, Gilbourne and Richardson 2005). [Table 2 near here]

\section{The Researchers}

The first author was a white 25 year old male who had previously conducted prolonged research within each high performance centre, and therefore, was familiar with the research environment, culture, and working practices (see [Authors] 2016). The second author, who was involved in the design and content of the workshops, was a health care professional council (HCPC) registered sport and exercise psychologist, a British Association of Sport and Exercise Sciences (BASES) accredited sport scientist, and a British Psychological Society (BPS) chartered psychologist who had consulted with the Lawn Tennis Association (i.e., govering body of Britsh tennis) as well as individual tennis players and parents for over 20 years.

\section{Data Collection}

A qualitative approach was used to explore tennis parents shared experiences of the programme as well as its perceived effect on their knowledge, affect and skills (Needleman and Needleman 1996). Within the current study, qualitative data was collected through social validation feedback forms, reflective diaries, emails, and post-intervention focus groups.

\section{Social Validation Feedback Form}

Following each workshop, qualitative social validation feedback forms were used to assess the perceived effectiveness of the workshop and establish how participants perceived, made sense of, and attached meaning to the workshop content (Wagstaff et al. 2013). Participants were also encouraged to identify topics they would like to receive more information on and to provide any 
comments or suggestions relating to the workshop format and design. A total of 111 feedback forms (76\% response rate) were collected during the programme (see Table 3). These forms were used as part of the action research process of monitoring and evaluating (Evans et al. 2000).

\section{Reflective Participant Diary}

After each workshop, participants were encouraged to keep an on-going reflective account of how the information they learnt and skills they were taught during workshops impacted on their parenting in tennis. Participants were given a reflective diary sheet and asked to provide their written reflections to the first author in person or by email. To facilitate this process, the first author often informally discussed participants' experiences and provided feedback to achieve a deeper level of reflection. Over the course of the programme, a total of 48 diary sheets (33\% response rate) were collected (see Table 3). [Table 3 near here]

\section{Researcher Reflexive Diary}

A reflexive diary was used to record field notes, which included observations and informal chats that related to the intervention and the progress being made (Evans et al. 2000, Hill et al. 2011, Wagstaff et al. 2013). Following each workshop, field notes were written to systematically reflect on the programme, understand the emerging situation, and modify the action if required.

\section{E-mail}

As logistics and the number of participants limited the individual face-to-face support each participant received, participants were encouraged to contact the lead researcher via email to discuss any issues or experience the participant chose to raise (Hill et al. 2011). Weekly emails were also used to increase adherence to the intervention and to maximise its intended impact.

\section{Focus Groups}

Semi-structured focus groups were used to explore participants shared (but not always the same) perceptions and experiences of the workshops as well as the overall impact of the programme. During each focus group, introductory questions were used to facilitate interaction within the group. Subsequent questions focused on exploring parents' reasons for participation, general experiences 
of the workshops, and percieved outcomes. Finally, questions explored the delivery of information and future education and support. Focus groups were conducted at each centre and ranged in duration from 52 to 85 minutes (Mean: 65.9, SD: 16.7).

\section{Data Analysis}

The first phase of data analysis involved the first author becoming immersed within the participants' experiences of the intervention by reading and re-reading social validation feedback forms, diary entries, and focus group transcripts. This was used to promote a high level of familiarity and understand participant's individual perceptions and the overall experiences of the intervention. Thematic analysis was then used to inductively analyse the data to generate initial codes and identify themes. Finally, recurring themes within these sources of data, along with the lead researcher's reflections, were presented as a realist tale (Sparkes and Smith 2014), which captured the systematic delivery process of the programme.

\section{Results}

\section{Introductory Session}

Following pre-intervention meetings with directors at each centre, in which their previous attempts to offer workshops for parents were discussed, the need to provide free, structured, and accessible education (i.e., whilst their children were training) for mini-tennis parents was established and six one-hour workshops across a three-month (12-week) period were provisionally agreed. Parents at each centre were invited by email to attend an introductory session and coaches were also asked to recommend attending during interactions with parents in the lead up to the session (Axford et al. 2012). A total of 17 parents attended an introductory session across all three centres (see Table 3). These parents were regularly attending the centres and felt it was good opportunity to learn how to better support their child. As one parent explained: "It sounded like an interesting subject area, I felt there wasn't a lot out there for what we do as parents, and there is not a lot of back up for us... and the convenience obviously, we are here, we are hanging around and it seemed like an ideal opportunity" (Parent 3 - Focus Group). Interestingly, the parents that attended 
appeared to be more willing to do so given that I (the first author) was delivering the programme. The following quote illustrates this point: "I think the difference is that you are not from here [the tennis centre] that you are from the university, that interested me more, it made it sound like you were the expert, the specialist, and that you are going to have all the answers for us" (Parent 2 Focus Group). However, these parents suggested that the majority of parents were either unable to attend the session due to work and/or family commitments or were not interested. As one mum stated: "Some parents are disinterested in it [parent education] because they think they know everything already!” (Parent 3 - Focus Group).

Based on the pre-intervention meetings, this introductory session started by explaining to parents, through the use of a task, how important they are in their child's psychological, social, and tennis development during childhood (age 5-10 years) (Wylleman and Lavallee 2004). The following quote illustrates the impact this had on parents: "I feel I am sometimes only there to transport him to lessons and hand over the money...I now realise there is greater emphasis on MY role which is more important than I thought at first” (Parent 2 - Feedback From). Following this, parents were then provided with an overview of British tennis parents education and support needs ([Authors] 2016) and a provisional outline of the programme content (see Table 2). Given my age and status as a non-parent, I used this as an opportunity to establish credibility. Despite my initial concerns, it was my perceived experience and knowledge of the area that gained parents buy in. One parent highlighted how important this was during one of the focus groups:

From the beginning you made it very clear that you had spent a lot of time in tennis centres, a lot of time with tennis parents and with coaches, so I think that information for me at the start made me appreciate that you do know what you are talking about, so we are not looking at you and thinking 'oh you are not a parent so you don't know' (Parent 5 - Focus Group).

Parents were then asked to provide feedback and identify any additional education and support needs in small groups. Encouragingly, feedback revealed that the programme "touches on 
all the important points and the topics covered are very relevant to parents" (Parent 18 - Feedback Form). Another parent explained how this captured her interest: "I can relate to all these issues, and look forward to finding out more" (Parent 8 - Feedback From). Providing parents with the opportunity to have an input into the design and content of the intervention and ensuring that the workshops were based on the actual needs of the participants was critical for engaging parents in the intervention (Axford et al. 2012).

The final part of the session provided parents with an opportunity to discuss the most suitable days, times, and locations for the workshops. As expected, parents' individual availability for workshops was largely determined by the days and times their child trained at the centre. These on-going discussions were used to establish and agree the days, times, and locations for the workshops that were most convenient in each centre. Despite this, parents highlighted a number of barriers to attending every workshop such as work commitments, looking after siblings, lift sharing or wanting to watch their child train. As a result, it was agreed that all participants would be provided with information packs including the workshop slides and supplementary materials.

\section{Workshop 1: Supporting Your Child During Mini-Tennis}

Following the introductory session, all mini-tennis parents at each centre were re-emailed the finalised dates, times, and locations and encouraged to attend the first workshops. At this point, three parents withdrew from the programme citing work and/or family commitments. Despite this, an additional 14 parents attended the first workshop increasing overall numbers to 27 (see Table 3) across the three centres and highlighted the value of several routes of referral (Axford et al. 2012). One parent later reflected on her reasons for attending the first workshop: "I received the [original] email but I didn't think it was for me, I just asked and heard it was really good and that's why I came" (Parent 16 - Focus Group).

Those that attended were introduced to the different types of parental involvement (i.e., unsupportive, supportive, and pressurising) and the factors that influence parents' involvement (i.e., 
parents' reasons for involvement, knowledge of tennis and the financial and time commitment) ([Authors] 2016). Through the use of an individual task, parents were encouraged to think about their own reasons for involvement and the goals they have for their children (Knight and Holt 2014). Parents were then asked to identify additional goals for their child's participation in tennis by emphasising the multiple benefits of tennis participation (i.e., psychological, physical, intellectual, and social benefits of participation in youth sport) (see Holt 2008). Parents felt that this had changed their goals and attitude towards mini-tennis. As one mum explained: "Seeing how tennis can produce an all-round employable person made me realise that I may waver too much towards performance and that participation is as important" (Parent 2 - Feedback From). Similarly, another parent felt these were: “Interesting points about the benefits of playing tennis which I didn't think about before, tennis is great for character building and life skills" (Parent 18 - Feedback Form)

The second section of the workshop focused on helping parents to understand how their knowledge of tennis can influence their type of involvement and specifically the informational and emotional support they can provide their child (Knight and Holt 2014). The workshop provided parents with an understanding of the demands, rules, and levels of tennis to ensure parents were able to relate to what their child is going through, adopt a realistic perspective, and be able to provide accurate feedback. One parent recalled during a focus group how understanding these levels helped her to manage her expectations: "I liked it when you did that pyramid and said 'you are here and then you've got Andy Murray at the top' and that was like the reality check wasn't it. I didn't realise how many levels there were to be honest!" (Parent 1 - Focus Group). Building on this, we discussed the physical, technical, tactical, and psychological demands children face on court. This enabled parents to realise the demands their children face when training and competing. For example, one mother explained: "It [the workshop] has given me more of an understanding of how my child is feeling when he is stood on the baseline in a competition, what is going through his head, and the worries that he has" (Parent 8 - Feedback From). To reinforce the workshop content, parents were provided with a newspaper article about the professional tennis tour (Bland, 2014) and 
encouraged to play a game of tennis to understand how difficult the sport is and be able to relate to and empathise with what their child goes through on court. The following quote was taken from a parent's diary:

Each match is so unpredictable, you can have a goal, you can have a game plan, but in the end you have to alter your perspective and goals as the game goes on. In the longer games there are peaks and troughs and players rarely stay in control for the whole match... The court looks so much bigger when you are down there about to serve! I have spent too many hours watching [Child's name] play and not really appreciating how difficult it is for him especially making the transition from orange ball to green ball. Sometimes I will say to him 'why did you play that shot at that particular time?' but from doing this I realise you only have a split second to decide which shot to play. It [understanding tennis] is critical to understand what children are going through and the pressures they face (Parent 2 - Diary).

However, some parents were struggling to find time to complete the tasks and their diary given their work and family commitments. Upon reflection, I concluded that although practical tasks remained an important and necessary part of the programme to reinforce learning, parents' would be given time at the start of each workshop to complete their reflective diary in order to minimise the workload outside of the session.

\section{Workshop 2: The Lawn Tennis Association's (LTA) Mini-Tennis Organisational System.}

At this stage in the programme, focus shifted towards the stage-specific needs of parents during mini-tennis (see [Authors] 2016). Workshop 2 focused on educating parents about the governing body's mini-tennis organisational system and aimed to reduce the organisational related stressors parents experience during this stage (Harwood and Knight 2009b). Parents were provided with information about the stages of mini-tennis (e.g., age groups, court sizes, and scoring system), how to enter mini-tennis tournaments (using the LTA's website), what grade of tournaments to enter, and how the mini-tennis ratings, rankings work (orange 1*, 1, 2 etc.) (see [Authors] 2016). Interestingly, the effectiveness of this workshop appeared be influenced by parents existing 
knowledge and experience. For instance, one parent who was new to tennis wrote: "It was very informative and useful. Understanding the different equipment, scoring systems, and some simple rules of tennis...I now feel I can relate to some of the things on court and also understand it all much better" (Parent 17 - Diary). Similarly, another parent whose child had recently started to compete felt that "the workshop was very useful, because it gave me information about the rating and ranking and what needs to be done to improve them and also what to expect during tournaments in terms of umpiring and cheating" (Parent 30 - Feedback From). Although more experienced parents noted that had already learnt much of this information, there was a general agreement that: "I wish there had been this sort of thing when we started... It [the workshop] would be very beneficial if you are new to tennis" (Parent 28 - Feedback From). After the workshop, parents were encouraged to walk around the centre and watch children at each mini-tennis stage and look out for differences in courts, equipment, and scoring systems.

Encouragingly, post workshop feedback at this point in the intervention suggested that parents felt the workshops were "very well structured and informative, easy to follow, and relate to real life experiences" (Parent 19 - Feedback Form), and that the parents were "very comfortable with [Author's name] now, delivery is always natural and not scripted" (Parent 8 - Feedback Form). Importantly, parents felt that the workshops were giving them an "opportunity to meet other parents to discuss strategies, and also with you (the expert), in a safe environment as opposed to snatched conversations on the courtside" (Parent 2 - Diary). This was reassuring given that creating a safe environment for learning is vital for engagement in adult education (Rogers and Freiberg 1994). Based on parents' feedback and my own reflections, more examples and opportunities for interaction were integrated into future workshops.

\section{Workshop 3 (Part 1): Child Development During Mini-Tennis.}

At the midway point, numbers had stabilised with 21 parents attending workshop 3 across the three centres (see Table 3). However, individual attendance fluctuated based on parents' work commitments, travel arrangements and/or family responsibilities. As one mum explained: "Because 
we lift share we don't all come every week because we have quite a journey (Parent 11 - Focus Group). Another parent added: "For me its logistics with the other children that I have to bring along with me, and whether or not they are going to be able to sit quietly through a session" (Parent 10 - Focus Group). Workshop 3 was split into two parts and focused on educating parents about child and talent development during mini-tennis (see [Authors] 2016). Part one of this workshop began by explaining children's psychological and social needs and how they change during mid to late childhood (see Weiss 2004). One parent wrote on her feedback form: "I have understood where my son is and that's a great benefit to support him better...I feel I can piece things together a bit better. I enjoyed the workshops as it focused on child development in general not just tennis development" (Parent 11 - Feedback Form).

This understanding served as the basis for the second half of the workshop, which focused on providing parents with an understanding of how to create an environment that develops feelings of intrinsic motivation and competence during childhood (Weiss 2004). This section started by helping parents to understanding how to enhance their child's intrinsic motivation through satisfying their need for autonomy, competence, and relatedness (Deci and Ryan 1985). Emphasis was placed on how parents' verbal and non-verbal communication creates a motivational climate and influences their child's task or ego goal orientation. Specifically, I explained to parents how to develop and maintain task-based competence through setting developmentally appropriate shortterm process goals, praising effort and progress, and avoiding social comparisons of ability (see Keegan et al. 2009). This made parents realise that "success is about making progress not necessarily winning" (Parent 9 - Feedback Form) during mini-tennis and that "praising effort rather than achievement can be a more effective way of improving performance" (Parent 9 - Feedback From). There was a general consensus that the workshop had provided parents with a "clearer idea on how to support my child effectively and to focus on effort, progress and improvement" (Parent 27 - Feedback From). In addition to developing and maintaining competence, parents were provided with a number of guidelines and recommendations to help their child feel relatedness and 
autonomy. One parent later explained during a focus group how this realisation had impacted on her decision-making:

We've tried to make tournaments more of a social event for [Child's name], we make sure we know who is going to be there, and he will either get there early and warm up with them or we make sure we stay behind at the end and he will have a play with them afterwards. We look to see who is in it, so I then know that I've got mums there that I can talk to, so then he sees it more as a social thing (Parent 2 - Focus Group).

Similarly, another mother explained how she was more aware of ensuring her daughter developed feelings of autonomy by involving her in basic decision making: "My daughter [9 year old] has recently decided she wants to play in a netball squad which is at the same time as a tennis session. We have gone with this as it's important to support her choice (as per this session) and also play other sports (especially team sports)" (Parent 11 - Diary). At the end of the workshop, parents were provided with a goal-setting chapter (i.e., Harwood, 2004) and encouraged to review their child's tennis environment (e.g., training groups and tournament schedule) to ensure it was conducive to developing intrinsic motivation. The following quote was taken from one parent's diary:

It was interesting to see how children are motivated and how this changes throughout their early development. It has made me take a step back and look at what motivates [Child's name] in his playing and also what influences we have in goal setting, tournament planning, lessons, and keeping a healthy home / tennis balance...I feel better armed with what to say / do, and that we need to talk with his coach more about where we are heading, short term mainly, about where he is playing in tournaments - when he needs a break - when he just needs to have fun with no pressure on results (Parent 2 - Diary).

\section{Workshop 3 (Part 2): Talent Developmental During Mini-tennis}

Part two of this workshop focused on the role of parents in facilitating talent development during mini-tennis. Parents were provided with an introduction to talent identification, its 
effectiveness, and its benefits and consequences (Vaeyens et al. 2008). Following this I explained the different talent development pathways and the strengths and weaknesses of following an early specialisation (Ericsson et al. 1993) or early diversification (Côté 1999) pathways during childhood/mini-tennis. Rather than select a pathway per se, parents were encouraged during a task to identify an individual pathway based on their child's age, psychosocial needs, and stage of development on three continuums: (a) short vs. long term view; (b) involvement in one sport vs. multiple sports; and (c) focus on deliberate practice vs. deliberate play. Parents felt that this section changed their beliefs about success in junior-tennis: "It has just made me think...I always thought that all your coaches wanted to see was win, win, win...but now I realise it's more about development, and I don't feel so much pressure from that and the pressure is not on my daughter" (Parent 1 - Focus Group). Parents used the information from the first half of the workshop to make an informed decision about their child's talent development pathway. The following quote captures this point: “The workshop was really useful, it identified in more detail my son's needs and helped to clarify talent ID pathways...we have decided to continue the multisport approach (tennis, football, cricket, and golf) as we feel it suits his needs/stage of learning” (Parent 29 - Diary).

Consistent with an early diversification approach, one mother explained how she had altered her daughters schedule to ensure she gets a broad range of social opportunities at this stage: "I've realised that it is a long pathway that we have started on and that tennis must be fun and I should make time for other activities like socialising with non-tennis friends. I have now cancelled some tournaments that we were due to enter to free up some time for her... and me!" (Parent 1 - Diary). For most parents, the workshops seemed to confirm their own thoughts about their child's tennis involvement and gave them confidence they were making the right decisions. For instance one parent wrote in her diary: "I thought this [workshop] was very useful, it has helped me to be clearer on our approach and I feel more confident in our approach, in the decisions/choices we are making for our son. It helped reinforce our feelings and gave us more information/detail” (Parent 29 Diary). Parents also explained how they felt more empowered and in control of their child's tennis. 
The following quote captures this point: "We can have a little bit more say with a little bit more ground knowledge and confidence, because it has always been their rules (the LTA and coaches), we are led by them, so I think it's made us more empowered. It's our child and we decide" (Parent 3 - Focus Group).

At the end of the workshop, parents were provided with recent review articles on early specialisation (including deliberate practice) (Baker and Young 2013) and early diversification (Pankhurst and Collins 2013) to reinforce the key messages from the workshop and encouraged to discuss their approach with their partners and coaches. Although a number of parents were still struggling to find time to complete take home tasks, the following diary extract highlights the effectiveness of these tasks in reinforcing and sharing knowledge: "The articles are really useful and informative, I enjoy reading them, they help to reinforce our feelings but also gave us more information and detail...I share the articles with my partner so we can make educated choices" (Parent 29 - Diary).

\section{Workshop 4: Competition Roles}

The penultimate workshop built upon the previous workshops and focused on educating parents about their roles within the specific context of competitions. The workshop began by educating parents when and how to engage in task-orientated communication with their child, how to set or reinforce short term process goals before a tennis match, and how to establish behavioural expectations (e.g., effort and sportspersonship) (Grolnick 2003). Parents were provided with examples and then encouraged to plan their next pre-match dialogue. Parents felt that this enabled them to communicate more effectively with their child. The following quote illustrates this point:

I feel that it [the task] has helped me to be more relaxed before tournaments. It has also helped me to know when and how to talk to my child at these times...I try not to give coaching tips myself, but I will back up coaching tips that they have been working on that week...I've become very aware of my body language and setting [short term process] goals before each match results in a happier parent and child (Parent 1 - Diary) 
Following this, parents were taught about the stress process, how to re-appraise stressful situations (e.g., child being cheated or losing), and given strategies to control emotions during a match (i.e., relaxation techniques). Parents were also explained how to ensure their body language is congruent with their pre-match verbal messages through a role playing scenario exercise. This not only made parents more aware of their body language but also changed the way they behave during matches. The follow quote captures this point:

After every point she [daughter] would look at me, so I used to tell her what she was doing wrong or right, but now I'm totally Ivan Lendl [body language example used in the workshop]...I'm able to control myself more...I sit still until the match finishes, less stress for me, less stress for her, it makes it more enjoyable (Parent 18 - Focus Group). Similarly, other parents explained during the focus group how this had made them more relaxed in the competitive environment: "At the weekend I was with some parents with children a year younger and they actually commented how laid back I was, you could see that they were going through the same anguishes I had gone through a year or so back. It's been so useful for everybody this sort of thing [the programme]" (Parent 4 - Focus Group). Finally, parents were explained about the timing and content of feedback. This included teaching communication skills (e.g., asking open questions and active listening), addressing behaviour (i.e., consequences for poor behaviour) and how to facilitate reflection and develop an action plan to encourage learning and improvement. This was explained through the use of a structured feedback framework. Overall, parents felt that that this workshop changed the way they interact with their child, which in turn improved their overall tournament experiences. As one parent explained:

With the goal setting before they play, I'm very much doing that, trying to make sure every match is positive, whatever the outcome is... I say to [Child's name] 'have a great match, enjoy it', I set her a goal like 'let's really try that serve you have been working on', and I have just found that whether she has won or lost, she might be a bit sad if she has lost but I can say 'oh those serves you were doing out wide were beautiful today, really, really 
nice'... and then she will say 'did you see that one?' And then you think she's okay, I'm okay. I'm not looking at it as a win or a loss, I'm looking at how she performs and where we are going to be in six months time, that's what it's made me think... you do want them to win but it's not the absolute be all and end all (Parent 1 - Focus Group).

\section{Workshop 5: Continual Learning and Support}

The final workshop was designed to ensure that parents would receive on-going support and continue to learn after the intervention. The workshop began by providing parents with a task to identify who or where they could turn to for education and support after the workshops had finished (Knight and Holt 2013a). As a group we then progressed through each source of support (e.g., coaches, support staff, other parents, books, online resources) identifying how it could help parents to support their child. Building a social support network prompted one mother to write in her diary: "It has helped me realise where, how, and when I can pick up information, help, and support i.e., parents supporting each other with their experiences and coaches with their expertise" (Parent 3 Feedback Form). Subsequently, parents were provided with examples taken from the literature of how to develop and maintain healthy relationships with coaches and other parents (e.g., Smoll et al. 2011).

Following this, the workshop focused on teaching parents how to reflect on and learn from their own experiences as a tennis parent. To do so, parents were provided with information on how and when to reflect (see Knowles et al. 2014) as well as examples of tennis parent reflections.

Following the workshop, parents were given a task of reflecting on their next training and tournament experience. Upon completion of the reflection task one parent wrote: "I learnt a lot, and will use this technique in tennis and everyday life. I hadn't realised how much I could learn from each tournament/training session just by looking back later that day. We only learn from the experiences we have and whether we have reacted well or negatively on reflection" (Parent 3 Diary). Another parent built on this point during the focus group:

I loved the reflection because it made me sit there and put it all into perspective. When you 
get it down on paper you think 'oh ok that wasn't as bad as I thought' and you recognise that you say different things when they come off court to what you say half an hour later in the car or the next morning - it's interesting to see how that conversation develops. Last time [Child's name] had a match that he wasn't happy with, I said 'well let's not talk about it now, you go off and play and we will talk about it later' and in the car he read a book and couple of hours later we were virtually home and he started talking about it in a totally different way to how he would have done. He did say to me 'is this what [Author's name] told you to do?' and I said 'shut up!' I did find that really useful because I think I was like a bull in a china shop at times with how I dealt with things (Parent 2 - Focus Group).

Post programme feedback revealed that parents enjoyed the range of discussions, practical tasks and opportunities to interact with other tennis parents. As one parent wrote: "I have really enjoyed learning together with other tennis parents as it is difficult to get support from friends/family who don't 'live' the pressures of the tennis world" (Parent 11 - Feedback From). Despite this, parents felt that future parent education programmes need to be made more accessible. One mother suggested that: "Workshops should be put online as well so that those of us who aren't able to come every week can still access it" (Parent 6 - Focus Group).

\section{Discussion}

Using an organisational action research design, the current study qualitatively evaluated the effectiveness of a tennis parent education programme designed to meet the needs of British tennis parents. This study was a response to calls within the literature to provide proactive interventions, which meet parents' stage-specific education and support needs, and thus enhance their expertise (Harwood and Knight 2015). Findings indicate that the programme was effective in changing parents' knowledge (i.e., cognitions), attitudes (i.e., beliefs and values), affective states and perceived behaviours in relation to the wide range of learning objectives (see Table 2).

In terms of knowledge, findings suggest that parents gained an improved understanding of tennis (e.g., understand rules, levels, and demands), the youth sport environment (e.g., tournament 
entry and talent ID system), children's psychosocial needs, and talent development pathways. Applying this understanding enabled parents to organise their child's tennis schedule and make informed decisions in relation to their child's tennis development (e.g., selecting a talent development pathway). However, the extent to which individual parent's knowledge changed appeared to be dependent upon their prior knowledge and experience as a tennis parent. This suggests that knowledge-based education would be most effective if provided to parents at the start of their involvement to negotiate the complex and challenging nature of initial sport socialisation (Dorsch et al. 2015). In addition to this, findings also illustrated how parents engaged in reflective practice to problem solve and recognised the importance of accessing other support systems following the intervention. Taken together, these findings highlight the effectiveness of providing parents with an extensive knowledge of the sport, the importance of accessing other support systems, and emphasising the role of self-development during their initial involvement in order to help them to 'learn the trade' of sport parenting (Harwood and Knight 2015).

Alongside knowledge-related changes, results indicate that the programme was also effective in altering beliefs, attitudes, and values in relation to their own reasons for involvement (i.e., holistic child development), the goal of junior-tennis (i.e., a task-orientated view of success in junior-tennis), and the causes of success in junior-tennis (i.e., learning, effort, and improvement/progress). Encouragingly, findings also suggest that the intervention was effective in changing parents' confidence, with parents reporting feeling more empowered in their role as tennis parents. Brustad (2011) suggested that the increasingly complex and professional nature of youth sport programmes are causing problems because parents do not feel empowered to respond to concerns about the lack of a sufficiently healthy sport environment for their child. Findings here suggest that the current study has gone some way to addressing this in-balance by providing parents with 'a voice' and empowering them through giving them the reassurance and confidence needed to trust their parenting instincts. Interestingly, parents enhanced confidence in their ability to support their child also appeared to act as a buffer against the extensive range of stressors and emotions 
British tennis parents experience leading to a more positive psychosocial experience. Overall, these outcomes align with research which has shown parental goals, the emotional intensity of the game, and perceived knowledge and experience of sport influence parents' behaviour and the nature of their communication (Knight and Holt 2014, Holt et al. 2008).

Turning attention towards parents' skills and behaviour, results suggested that the intervention led to improved communication skills, which enabled parents to engage in more positive and effective interactions with their child within the context of competition. For instance, parents reported providing task-orientated pre-match communication (i.e., emphasising effort, enjoyment, and skill development), facilitating process goal setting, matching body language with pre-match messages, and providing positive and constructive feedback based on pre-match goals and behavioural expectations. These behaviours are largely consistent with the supportive parental behaviours and reactions preferred by child-athletes at competitions (Knight et al. 2010, Holt et al. 2008) and suggest that parents were able to create a task-involved motivational climate, which has been associated with a number of desirable developmental outcomes for child-athletes (e.g., perceived competence, self-esteem, intrinsic motivation, and moral attitude) (Keegan et al. 2009).

Beyond programme outcomes, the current study also extends previous research (e.g., Dorsch et al. 2016, Harwood and Swain 2002, Smoll et al. 2007) by providing an insight into the underlying mechanisms that influence learning in sport parent education programmes. Findings here suggest that when tennis parents' basic learning needs are met (e.g., a safe and supportive learning environment) they construct knowledge through various different sources and situations (e.g., formal, self-directed, and informal learning) building on their existing knowledge and experience to alter or create more organised and interrelated cognitive structures that govern their organisational, decision making, intra-personal, and interpersonal skills. Therefore, the current study offers an insight into complex factors that play a part in the learning process of sport parents and that, like coaching, there is no one comprehensive theory of learning upon which to base sport parent research and practice (Cushion et al. 2010). As a result, practitioners are encouraged to integrate 
different ways of thinking and learning within sport parent education programmes. Similar to findings from research in coaching (e.g., Stoszkowski and Collins 2015) peer discussion appears to play a particularly important role in this learning process. From an applied perspective, this illustrates the importance of informal learning and the role that parent education programmes can play in providing a platform for such interaction and experience sharing. Overall, these findings extend our understanding of the potential benefits of encouraging interactions between parents (Knight and Holt 2013b), and suggest that group based parent workshops represents one way in which parents (and their children) can be successfully integrated and socialised into organised youth sport systems.

From a practical point of view, the current study provides a number of recommendations in relation to the design and content of tennis parent interventions. Focusing initially on factors associated with participants' engagement, there were a number of generic strategies that were effective in facilitating retention during the intervention. These included: creating a safe inclusive learning environment (Rogers and Freiberg 1994), giving parents an input into the programme content, encouraging parents to interact and share experiences (Merriam and Leahy 2005), ensuring education was linked to the actual practice setting and needs of participants, building relationships with parents, making workshops accessible (see Axford et al. 2012), and providing supplementary learning material (e.g., workshop slides and articles). Supplementary learning materials appear to be particularly important when delivering a series of progressive workshops to prevent parents from falling behind if they are unable to attend a session. These strategies were also associated with successful learning transfer and the final outcomes of the intervention (Merriam and Leahy 2005). Despite this, the long-term effectiveness of the intervention is likely to be dependent upon the messages being continually reinforced by key stakeholders (e.g., directors and coaches) who interact with parents on a regular basis. With this in mind, there appears to be a need for practitioners (e.g., sport psychologists) or mentors (e.g., experienced tennis parents) to be embedded within high performance centres alongside other support provisions (e.g., strength and conditioning 
coaches) to provide on-going support to parents (and young athletes) and to ensure educational outcomes are maintained.

The current study should also be considered against its limitations. Firstly, the current study was tailored for the needs of British tennis parents as a group, rather than the needs of individual parents per se. Researchers are encouraged to explore the ways in which group based programmes can be further individualised for parents based on their existing knowledge and experience (i.e., recommend workshops based on pre-programme evaluations). Secondly, the current study focused on parents' subjective perceptions of change following the intervention. Although the findings reported here are both rich and promising, alternative research designs (e.g., longitudinal research) and evaluation methods that reflect the domain of learning targeted (e.g., behavioural observation) could be used to evaluate the effectiveness of future sport parent interventions. Future research should also explore if, and how, intervention outcomes are sustained over time. Finally, the current study was to some extent limited by low participation and intermittent attendance. Unfortunately, such problems are common in face-to-face parent education programmes (Breitenstein et al. 2014). Future research is needed to explore whether alternative delivery methods (i.e., web-based delivery) can be used to increase the reach and accessibility of sport parent education programmes (Breitenstein et al. 2014).

In conclusion, the current study provides evidence to suggest that group-based parent education programmes can generate perceived improvements in tennis parents' knowledge, attitudes (i.e., beliefs and values), and skills in relation to a range of learning objectives. In addition to this, original insights are provided in relation to how these objectives were achieved. In doing so, the current study has answered long-standing calls to start educating and supporting tennis parents (Gould et al. 2006) and to create a better understanding of how to design and deliver programmes in real-world settings (Holt and Knight 2014). We believe that this study can act as a platform for more evidence-based tennis parent interventions and stimulate the development, implementation and evaluation of parent education programmes in other sports. 


\section{References}

Axford, N., et al., 2012. Engaging parents in parenting programs: Lessons from research and practice. Children and Youth Services Review, 34, 2061-2071. doi:10.1016/j.childyouth.2012.06.011.

Anderson, L.W., et al., 2001. A taxonomy for learning, teaching, and assessing: A revision of Bloom's taxonomy of educational objectives. New York: Longman

Baker, J. and Young, B., 2014. 20 years later: deliberate practice and the development of expertise in sport. International Review of Sport and Exercise Psychology, 7(1), 135-157.

Brustad, R. J., 2011. Enhancing coach-parent relationships in youth sports: Increasing harmony and minimizing hassle. A commentary. International Journal for Sports Science and Coaching, 6(1), 33-36. doi:10.1260/1747-9541.6.1.33

Breitenstein, S.M., Gross, D., and Christophersen, R., 2014. Digital delivery methods of parenting training interventions: A systematic review. Worldviews on Evidence-Based Nursing, 11 (3), 168-176.

Bland, A. 2014, January 11. Jamie Baker's break point: A tennis nomad exits the planet's cruelest sport. The Independent. Retrieved from http://www.independent.co.uk/sport/tennis/jamiebakers-break-point-a-tennisnomad-exits-the-planet-s-cruellest-sport-9046491.html

Côté, J., 1999. The influence of the family in the development of talent in sport. The Sport Psychologist, 13, 395- 417.

Cushion, C.J., et al., 2010. Coach learning \& development: A review of literature. Leeds: Sports Coach UK.

Deci, E. L. and Ryan, R. M., 1985. Intrinsic motivation and self-determination in human behavior. New York: Plenum.

Dorsch, T.E., et al., 2016. The impact of evidence-based parent education in organized youth sport: A pilot study. Journal of Applied Sport Psychology. DOI: 10.1080/10413200.2016.1194909 Dorsch, T.E., Smith, A.L., and McDonough, M.H., 2015. Early socialization of parents through 
organized youth sport. Sport, Exercise, and Performance Psychology, 4 (1), 3-18.

Ericsson, K.A., Krampe, R.T., and Teschromer, C., 1993. The role of deliberate practice in the acquisition of expert performance. Psychological Review, 100, 363-406.

Evans, L., Fleming, S., and Hardy, L., 2000. Situating action research: A response to Gilbourne. The Sport Psychologist, 14, 296-303.

Gould, D., et al., 2006. Understanding the role parents play in tennis success: A national survey of junior tennis coaches. British Journal of Sports Medicine, 40, 632-636. doi:10.1136/bjsm.2005.024927.

Gould, D., et al., 2008. The role of parents in tennis success: Focus group interviews with junior coaches. The Sport Psychologist, 22, 18-37.

Gilbourne, D. and Richardson, D., 2005. A practitioner-focused approach to the provision of psychological support in soccer: Adopting action research themes and processes. Journal of Sports Sciences, 23(6), $651-658$

Grolnick, W. S., 2003. Psychology of parenting control: How well-meaning parenting backfires. Mahwah, NJ: Lawrence Erlbraum.

Harwood, C.G. 2004. Goals: More than just the score. In S. Murphy (Ed), The Sport Psych Handbook (pp.19-36). Champaign, IL: Human Kinetics.

Harwood, C.G. and Knight, C.J., 2009a. Understanding parental stressors: An investigation of British tennis-parents. Journal of Sports Sciences, 27, 339-351. doi:10.1080/02640410802603871.

Harwood, C.G. and Knight, C.J., 2009b. Stress in youth sport: A developmental investigation of tennis parents. Psychology of Sport and Exercise, 10, 447-456. doi:10.1016/j.psychsport.2009.01.005

Harwood, C.G. and Knight, C. J., 2015. Parenting in youth sport: A position paper on parenting expertise. Psychology of Sport and Exercise, 16, 24-35. doi:10.1016/j.psychsport.2014.03.001 Harwood, C. G. and Swain, A. B., 2002. The development and activation of achievement goals 
within tennis II: A player, parent, and coach intervention. The Sport Psychologist, 16, 111137.

Herr, K. and Anderson, G.L., 2005. The action research dissertation: A guide for students \& faculty. London: Sage.

Hill, D.M., et al., 2011. Alleviation of choking under pressure in elite golf: An action research study. The Sport Psychologist, 25, 465-488.

Holt, N. L., 2008. Positive youth development through sport. Abingdon, Oxon: Routledge.

Holt, N.L. and Knight. C.J., 2014. Parenting in youth sport: From research to practice. London: Routledge.

Holt, N. L., et al., 2008. Parental involvement in competitive youth sport settings. Psychology of Sport and Exercise, 9(5), 663-685. doi:10.1016/j.psychsport.2007.08.001

Keegan, R.J., et al., 2009. A qualitative investigation exploring the motivational climate in early career sports participants: Coach, parent and peer influences on sport motivation. Psychology of Sport and Exercise, 10, 361-372.

Knight, C. J., Boden, C. M., and Holt, N. L., 2010. Junior tennis players' preferences for parental behaviors at tournaments. Journal of Applied Sport Psychology, 22, 377-391. doi:10.1080 $/ 10413200.2010 .495324$

Knight, C. J. and Holt, N. L., 2013a. Parents' experiences at junior tennis tournaments in Western Australia. Sport, Exercise, and Performance Psychology, 2, 173-189. http://dx.doi.org/10.1037/a0031203.

Knight, C. J. and Holt, N. L., 2013b. Strategies used and assistance required to facilitate children's involvement in competitive tennis: Parents' perspectives. The Sport Psychologist, 27, 281291.

Knight, C. J. and Holt, N. L., 2014. Parenting in youth tennis: Understanding and enhancing children's experiences. Psychology of Sport and Exercise, 15, 155-164.

Knowles, Z., et al., 2014. Reflective practice in the sport and exercise sciences, contemporary 
issues. Routledge: New York.

Lauer, L., et al., 2010. Parental behaviors that affect junior tennis player development. Psychology of Sport and Exercise, 11, 487-496. doi:10.1016/j.psychsport.2010.06.008.

Merriam, S.B. and Leahy, B., 2005. Learning transfer: A review of the research in adult education and learning. Journal of Lifelong Learning, 14, 1-24.

Needleman, C. and Needleman, M., 1996. Qualitative methods for intervention research. American Journal of Industrial Medicine, 29, 329-337.

Pankhurst, A. and Collins, D., 2013. Talent identification and development: The need for coherence between research, system, and process. Quest, 65 (1), 83-97.

DOI: $10.1080 / 00336297.2012 .727374$

Reason, P. and Bradbury, H., 2001. Handbook of action research: Participative inquiry and practice. London: Sage Publications.

Rogers, C. and Freiberg, H.J., 1994. Freedom to learn. 3rd ed. New York: Prentice Hall.

Smoll, F. L., Smith, R. E., and Cumming, S. P., 2007. Effects of coach and parent training on performance anxiety in young athletes: A systemic approach. Journal of Youth Development, 2 (1), 0701FA001

Smoll, F. L., Cumming, S. P., and Smith, R. E., 2011. Enhancing coach-parent relationships in youth sports: Increasing harmony and minimizing hassle. International Journal of Sports Science and Coaching, 6, 13-26. doi:10.1260/1747-9541.6.1.13.

Sparkes, A. C. and Smith, B., 2014. Qualitative research methods in sport, exercise and health: From product to process. Abingdon: Routledge.

Stoszkowski, J. and Collins, D., 2015. Sources, topics and use of knowledge by coaches. Journal of Sports Sciences, 1-9. DOI: 10.1080/02640414.2015.1072279

Vaeyens, R., et al., 2008. Talent identification and development programmers in sport. Sports Medicine, 38, 703-714.

Wagstaff, C.R.D., Hanton, S., and Fletcher, D., 2013. Developing emotion abilities and regulation 
strategies in a sport organization: An action research intervention. Psychology of Sport and Exercise, 14, 476-487.

Weiss, M.R., 2004. Developmental sport and exercise psychology: A lifespan perspective (pp. 503524). Morgantown, WV: Fitness Information Technology.

Wylleman, P. and Lavallee, D., 2004. A developmental perspective on transitions faced by athletes. In M. Weiss (Ed.), Developmental sport and exercise psychology: A lifespan perspective (pp. 507-527). Morgantown, WV: Fitness Information Technology. 
4 Table 1. Participant Demographics

\begin{tabular}{|c|c|c|c|c|c|c|c|c|c|c|c|c|c|c|}
\hline \multirow[t]{2}{*}{ Population } & \multirow[b]{2}{*}{$\mathrm{n}$} & \multicolumn{3}{|c|}{ Player Age (Years) } & \multicolumn{2}{|c|}{ Gender } & \multicolumn{4}{|c|}{ Player Standard } & \multirow{2}{*}{$\begin{array}{c}\begin{array}{c}\text { Workshops } \\
\text { attended }\end{array} \\
M\end{array}$} & \multicolumn{3}{|c|}{ Years of Experience } \\
\hline & & $M$ & $S D$ & Range & Male & Female & Club & County & Regional & National & & $M$ & $S D$ & Range \\
\hline Centre 1 Parents & 6 & 9 & 0 & $9-9$ & 1 & 5 & 0 & 1 & 4 & 1 & 5.5 & 5 & 2.10 & $2-8$ \\
\hline Centre 2 Parents & 10 & 6.39 & 1.55 & $5-9$ & 1 & 9 & 6 & 1 & 1 & 2 & 4 & 2.75 & 1.72 & $1-6$ \\
\hline Centre 3 Parents & 15 & 8.13 & 0.52 & $7-9$ & 4 & 11 & 6 & 5 & 2 & 2 & 4.13 & 3.37 & 3.23 & $1-13$ \\
\hline Focus Groups & 19 & 7.91 & 1.20 & $5-9$ & 4 & 15 & 8 & 3 & 5 & 3 & N/A & 3.63 & 3.08 & $0.5-8$ \\
\hline
\end{tabular}

5

6

7

8

9

10 


\begin{tabular}{|c|c|c|c|c|}
\hline Workshop & Title & Workshop Learning Objectives & Workshop Content & Workshop/Take Home Tasks \\
\hline & $\begin{array}{l}\text { Introduction to } \\
\text { the Intervention }\end{array}$ & $\begin{array}{l}\text { Following this workshop parents should be able to: } \\
\text { - Appreciate how important they are in their } \\
\text { child's tennis development } \\
\text { - Acknowledge the value of tennis parent education } \\
\text { programmes }\end{array}$ & $\begin{array}{l}\text { - The importance of parents in child-athletes } \\
\text { development } \\
\text { - Overview of the tennis parent research } \\
\text { - Design, content, and delivery of the } \\
\text { programme }\end{array}$ & $\begin{array}{l}\text { - Ordering task: Who is the most } \\
\text { important person in your child's } \\
\text { mini-tennis development? } \\
\text { - Small group discussion: } \\
\text { Feedback on proposed } \\
\text { workshop design and content } \\
\text { - Group discussion: Establishing } \\
\text { a suitable day, time and } \\
\text { location for the workshops }\end{array}$ \\
\hline 1 & $\begin{array}{l}\text { Supporting your } \\
\text { child during } \\
\text { mini-tennis }\end{array}$ & $\begin{array}{l}\text { - Adopt multiple goals for their child's tennis } \\
\text { involvement } \\
\text { - Manage their expectations } \\
\text { - Explain the rules, levels, and demands of tennis } \\
\text { - Empathise with their child's on court experiences } \\
\text { - Prepare for the financial and time commitment } \\
\text { of mini-tennis participation }\end{array}$ & $\begin{array}{l}\text { - Types of parental involvement (Un- } \\
\text { supportive, supportive, pressurising) } \\
\text { - Providing informational, emotional, and } \\
\text { tangible support: } \\
\text { - Multiple benefits of tennis participation } \\
\text { - Knowledge of tennis } \\
\text { - Financial and time commitment }\end{array}$ & $\begin{array}{l}\text { - Individual task: What are your } \\
\text { goals for your child's } \\
\text { involvement in tennis? } \\
\text { - Take home reading: Newspaper } \\
\text { article (Bland, 2014) } \\
\text { - Take home task: Play a game of } \\
\text { tennis with your child }\end{array}$ \\
\hline 2 & $\begin{array}{l}\text { The LTA's } \\
\text { mini-tennis } \\
\text { organisational } \\
\text { system }\end{array}$ & $\begin{array}{l}\text { - Explain the stages of mini-tennis } \\
\text { - Enter their child into an appropriate level } \\
\text { tournament based on their age and rating } \\
\text { - Plan their child's schedule to help them improve } \\
\text { their rating and ranking } \\
\text { - Explain how the LTA's talent identification } \\
\text { system works }\end{array}$ & $\begin{array}{l}\text { - The stages, equipment, court sizes, and } \\
\text { scoring system of mini-tennis } \\
\text { - Mini-tennis tournament entry } \\
\text { - The LTA's mini-tennis ratings and ranking } \\
\text { system } \\
\text { - The LTA's talent identification and } \\
\text { development system }\end{array}$ & $\begin{array}{l}\text { - Take home task: Join British } \\
\text { Tennis and familiarise yourself } \\
\text { with each section of the LTA } \\
\text { website } \\
\text { - Take home task: Walk around } \\
\text { the centre and look out for } \\
\text { differences in court sizes, } \\
\text { equipment and scoring. }\end{array}$ \\
\hline \multirow[t]{2}{*}{3 (Part 1) } & \multirow[t]{2}{*}{$\begin{array}{l}\text { Child } \\
\text { development } \\
\text { during mini- } \\
\text { tennis }\end{array}$} & $\begin{array}{l}\text { - Identify their child's psychosocial needs during } \\
\text { childhood } \\
\text { - Adopt a task-orientated view of success in junior- } \\
\text { tennis }\end{array}$ & $\begin{array}{l}\text { - Psychosocial needs during childhood } \\
\text { - Introduction to motivation in mini-tennis } \\
\text { - Developing and maintaining motivation: } \\
\text { autonomy, competence, and relatedness }\end{array}$ & $\begin{array}{l}\text { - Individual task: What motivates } \\
\text { your child to play tennis? } \\
\text { - Take home reading: Goal } \\
\text { setting chapter (Harwood, } \\
\text { 2004). }\end{array}$ \\
\hline & & - Create an intrinsically motivating mini-tennis & - Short term performance and process goal & - Take home task: Review your \\
\hline
\end{tabular}


environment

3 (Part 2) Talent

development

during mini-

tennis

- Evaluate the strengths and weaknesses of following different talent development pathways

- Select a talent development pathway to follow during mini-tennis based on their child's needs

Competition Roles

Continual learning and support
- Engage in task-orientated verbal interactions with their child in the competition context

- Facilitate short term pre match goal setting

- Manage the range emotional demands of they experience during competition

- Demonstrate task-orientated body language during matches

- Identify their social support network

- Appreciate the importance of social support

- Develop and maintain healthy relationships with coaches and other parents.

- Reflect on and learn from their experiences setting
- Introduction to talent development

- Early specialisation vs. early diversification strengths and weaknesses

- Selecting a pathway during mini-tennis:

factors to consider
- How to communicate before a match

- How to control emotions and body language during a match

- When and how to communicate post match child's tennis environment (training groups and tournament schedule) to ensure it is conducive for maintaining intrinsic motivation

- Individual task: Select a talent development pathway

- Take home reading: Review articles on early specialisation (Baker \& Young, 2013) and early diversification (Pankhurst \& Collins, 2013)

- Take home task: Discuss your talent development approach with your partner/coach

- Individual task: Plan pre-match dialog

- Group task: Progressive Muscular Relaxation

- Role play: Body language responses to match scenarios

- Role play: Post match feedback scenario

- Take home task: Implement pre, during and post-match communication in competition

- Who or where to turn to for education and support

- Informal learning: how each source of social support can be helpful

- How to develop and maintain relationship

- Self-directed learning: reflective practice
- Individual task: Write down who or where you can turn to for education and support and how this support can be helpful

- Take Home Task: Reflect on your next tournament experience 
3 Table 3. Workshop Schedule, Participants, Attendance and Data Collected by Centre

4

5

6

\begin{tabular}{|c|c|c|c|c|c|c|c|c|c|}
\hline & & $\begin{array}{l}\text { Introductory } \\
\text { Session }\end{array}$ & Workshop 1 & Workshop 2 & $\begin{array}{c}\text { Workshop } 3 \\
\text { (Part 1) }\end{array}$ & $\begin{array}{c}\text { Workshop } 3 \\
\text { (Part 2) }\end{array}$ & Workshop 4 & Workshop 5 & Focus Group \\
\hline \multirow{4}{*}{ Centre 1} & Participants & $n / a$ & 6 & 6 & 6 & 6 & 6 & 6 & 6 \\
\hline & Attendance & 9 & 6 & 5 & 4 & 5 & 4 & 5 & 4 \\
\hline & $\begin{array}{l}\text { Feedback } \\
\text { Form }\end{array}$ & 9 & 4 & 5 & 3 & 5 & 3 & 4 & $\mathrm{n} / \mathrm{a}$ \\
\hline & Diary & $\mathrm{n} / \mathrm{a}$ & 3 & 2 & 1 & 2 & 1 & 2 & $\mathrm{n} / \mathrm{a}$ \\
\hline \multirow{4}{*}{ Centre 2} & Participants & $\mathrm{n} / \mathrm{a}$ & 9 & 10 & 10 & 10 & 10 & 10 & 10 \\
\hline & Attendance & 4 & 7 & 6 & 9 & 7 & 8 & 7 & 6 \\
\hline & $\begin{array}{l}\text { Feedback } \\
\text { Form }\end{array}$ & 4 & 6 & 6 & 5 & 7 & 6 & 7 & $\mathrm{n} / \mathrm{a}$ \\
\hline & Diary & $\mathrm{n} / \mathrm{a}$ & 3 & 6 & 4 & 4 & 4 & 2 & $\mathrm{n} / \mathrm{a}$ \\
\hline \multirow{4}{*}{ Centre 3} & Participants & $\mathrm{n} / \mathrm{a}$ & 12 & 15 & 15 & 15 & 15 & 15 & 15 \\
\hline & Attendance & 4 & 11 & 11 & 8 & 8 & 9 & 9 & 9 \\
\hline & $\begin{array}{l}\text { Feedback } \\
\text { Form }\end{array}$ & 4 & 8 & 3 & 2 & 5 & 9 & 6 & $\mathrm{n} / \mathrm{a}$ \\
\hline & Diary & $\mathrm{n} / \mathrm{a}$ & 2 & 0 & 1 & 5 & 4 & 2 & $\mathrm{n} / \mathrm{a}$ \\
\hline \multirow[t]{4}{*}{ Total } & Participants & $\mathrm{n} / \mathrm{a}$ & 27 & 31 & 31 & 31 & 31 & 31 & 31 \\
\hline & Attendance & 17 & 24 & 22 & 21 & 20 & 21 & 21 & 19 \\
\hline & $\begin{array}{l}\text { Feedback } \\
\text { Form }\end{array}$ & 17 & 18 & 14 & 10 & 17 & 18 & 17 & $\mathrm{n} / \mathrm{a}$ \\
\hline & Diary & $\mathrm{n} / \mathrm{a}$ & 8 & 8 & 6 & 11 & 9 & 6 & $\mathrm{n} / \mathrm{a}$ \\
\hline
\end{tabular}

